\title{
GRANULOMA INGUINALE WITH LESION ON THE LOWER LIP
}

REPORT OF A CASE

B. BARKER BEESON, M.D.

CHICAGO

In connection with the paper of Drs. Parounagian and Goodman, which appeared in the May number of the Archives of Dermatology AND SyPHILOLOGY, the following case report seems worthy of attention:

\section{CASE REPORT}

A negro affected with granuloma inguinale was seen by Dr. Fernando Terra, professor of dermatology at the University of Rio de Janeiro. The patient first exhibited ulcers of the groin and later an ulcer on the lower lip, from which, as well as from the inguinal lesion, the characteristic organisms were recovered. He found only seven cases with this combination of symptoms in the literature. This is of interest because of the statement by Drs. Parounagian and Goodman: "As far as we know there has been but one other case with lesions about the lip, reported by Sequeira." Terra's patient was cured by intravenous injections of tartar emetic. He exhibited this case before the Brazilian Dermatological Society in 1917, and also reported it in extenso in the Annals of the Faculty of Medicine of Rio de Janeiro for that year. 


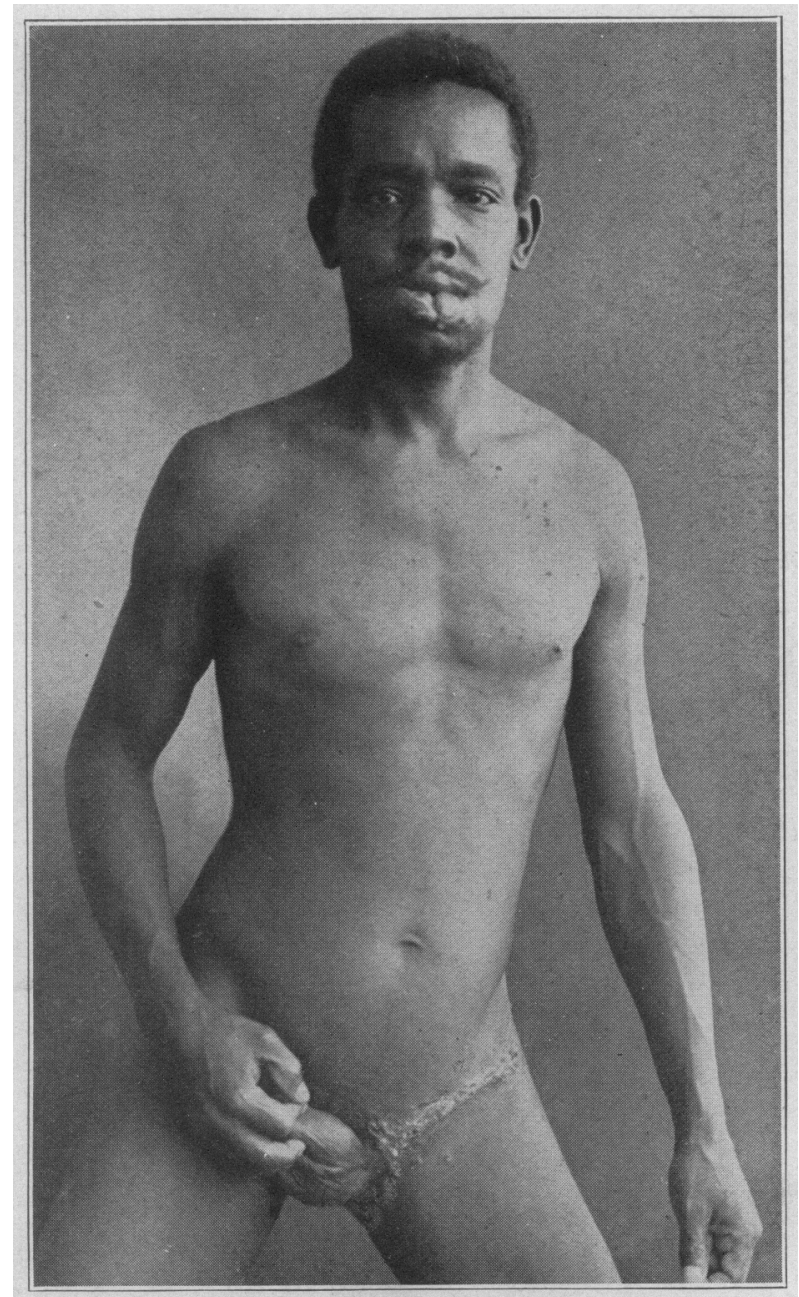

Granuloma inguinale with lesion on lower lip. Dr. Terra's patient. 